\title{
ESTUDO DE VIABILIDADE ECONÔMICA E FINANCEIRA ENTRE AQUISIÇÃO DE MÁQUINA OU TERCEIRIZAÇÃO: estudo de caso em uma indústria de confecções
}

\author{
Carla Elieze LEIDENS ${ }^{1}$
}

Mauro Alberto NUSKE²

Douglas FAORO ${ }^{3}$

Jocias Maier ZANATTA ${ }^{3}$

\begin{abstract}
${ }^{1}$ Bacharel em Administração pela Sociedade Educacional Três de Maio (SETREM). carla.leidens@ @otmail.com
2Mestre em Engenharia da Produção pela Universidade Federal de Santa Maria (UFSM), Especialista em Administração Financeira, Bacharel em Administração. Professor, Pesquisador e Procurador Institucional da Sociedade Educacional Três de Maio (SETREM). mauronuske@ setrem.com.br
\end{abstract}

${ }^{3}$ Mestre em Modelagem Matemática pela Universidade Regional do Noroeste do Estado do Rio Grande do Sul (UNIJUI). Professor da Sociedade Educacional Três de Maio (SETREM). douglasfaoro@gmail.com

${ }^{4}$ Mestre em Desenvolvimento pela Universidade Regional do Noroeste do Estado do Rio Grande do Sul (UNIJUI), Especialista em Gestão Financeira, auditoria e controladoria, Bacharel em Administração. Professor do Curso de Bacharelado em Administração da Sociedade Educacional Três de Maio (SETREM). jociaszanatta@ setrem.com.br

Recebido em: 06/07/2016 - Aprovado em: 19/03/2017 - Disponibilizado em: 01/07/2017

\begin{abstract}
RESUMO
O objetivo deste estudo é analisar a viabilidade econômica e financeira entre a aquisição de uma máquina de tecelagem comparando com a alternativa de terceirização de parte deste serviço, sendo que o problema de pesquisa visava descobrir qual opção é mais rentável para a empresa. Para tanto, utilizou-se a abordagem dedutiva, qualitativa e quantitativa, além dos procedimentos descritivo, comparativo e estudo de caso. Os dados foram coletados utilizando-se de técnicas como a observação, a entrevista e a pesquisa documental, os quais posteriormente foram analisados com o auxílio do software Excel $^{\circledR}$ e da análise de conteúdo. Após o levantamento do histórico de produção da indústria de confecções, analisou-se a previsão de demanda futura para o período de 01 (um) ano, e com base nas informações coletadas e nos dados disponibilizados pela empresa estudada, foi possível elaborar o fluxo de caixa e a Demonstração do Resultado do Exercício (DRE), permitindo também a realização da análise de indicadores, composta pelo Valor Presente Líquido (VPL), Taxa Interna de Retorno (TIR) e Payback (retorno de capital), bem como a apresentação da alternativa mais vantajosa para a indústria de confecções. Baseando-se no presente estudo, verifica-se que a terceirização é a alternativa mais indicada para a empresa estudada, se a mesma mantiver a produção atual, no entanto, a aquisição de máquina passa a ser uma alternativa viável e também a mais vantajosa para a indústria de confecções, se a mesma aumentar a produção e seu faturamento, em pelo menos $20 \%$.
\end{abstract}

Palavras-chave: Máquina de tecelagem. Indústria de confecções. Terceirização.

\begin{abstract}
The aim of this study is to analyze the economic and financial feasibility of acquiring a weaving machine compared to the alternative of outsourcing this service, and the research problem aimed to find out which option is more profitable for the company. For this, we used the deductive approach, qualitative and quantitative, in addition to descriptive procedures, comparative case study. Data were collected using techniques such as observation, interviews and documentary research, which were later analyzed with the aid of Excel software and content analysis. After lifting the production history of the clothing industry, analyzed the prediction of future demand for the period of one (01) years, and based on the collected information and data provided by the company studied, it was possible to prepare the flow box and the Income Statement (DRE), also allowing the realization of analysis of indicators, composed of the Net Present Value (NPV), Internal Rate of Return (IRR) and Payback (return of capital), and the presentation of alternative most advantageous for the garment industry. Based on the present study, it appears that outsourcing is the most suitable alternative for the company studied, whether it maintains the current production, however, the machine acquisition becomes a viable alternative and also advantageous to the garment industry, the same increase production and billing, at least $20 \%$.
\end{abstract}

Keyworks: Weaving machine. Clothing industry. Outsourcing. 


\section{INTRODUÇÃO}

Atualmente, o mercado de confecções encontra-se em expansão, fomentado, em especial, pela preocupação das pessoas com a aparência, o desejo de vestir-se bem, acompanhando as tendências da moda, assim como pela importância que o visual possui no mercado de trabalho. (Emprego e Renda-E \& $\mathrm{R}, 2013)$.

A indústria de confecções, objeto do estudo, localizada na região Noroeste do estado do Rio Grande do Sul, vivencia o crescimento deste segmento, mas em alguns períodos do ano apresenta dificuldades para atender a demanda por seus produtos, havendo a necessidade de terceirizar parte do serviço de tecelagem.

Neste contexto, o presente estudo teve como objetivo geral analisar a viabilidade econômica e financeira entre a aquisição de uma máquina de tecelagem comparando com a alternativa de terceirização, visando descobrir qual opção é mais rentável para a empresa.

Este trabalho está estruturado em quatro tópicos. No primeiro têm-se a introdução, e no segundo o referencial teórico, que aborda os principais assuntos relativos ao tema. $\mathrm{O}$ terceiro tópico refere-se aos métodos do estudo, onde foi utilizada a abordagem dedutiva, qualitativa e quantitativa, além dos procedimentos descritivo, comparativo e estudo de caso. No quarto tópico apresentamse os resultados obtidos com o estudo, baseando-se nos dados coletados e nas informações levantadas, visando responder ao problema proposto e aos objetivos elencados.

\section{FUNDAMENTAÇÃO TEÓRICA}

\subsection{Análise de investimentos}

As técnicas de análise de investimentos são muito úteis na avaliação de um projeto, visto que, as mesmas permitem a obtenção de informações sobre o retorno do capital investido, contribuindo na tomada de decisão e aumentando a probabilidade de se ter êxito com o investimento.

O objetivo principal da análise de investimentos é servir de ferramenta analítica para auxiliar no processo de tomada de decisões entre investimentos alternativos (ANGELO; SILVEIRA, 2000). O investimento pode ainda ser definido como sendo um conjunto de procedimentos, que inclui métodos e técnicas que permitem avaliar e selecionar investimentos e contribuir para a meta da empresa de maximização da riqueza (HOJI, 2003; GITMAN, 2004).

\subsubsection{Valor presente líquido (VPL)}

Na visão de Castelo Branco (2005), o Valor Presente Líquido (VPL) é uma técnica sofisticada, cujo valor é resultado da subtração entre o valor presente das entradas ou saídas de caixa e o valor do investimento inicial. Quando o VPL for maior do que zero, o projeto deve 
ser aceito e quando for menor deve ser recusado.

A figura 1 apresenta a fórmula para o cálculo do valor presente líquido:

Figura 1 - Valor presente líquido

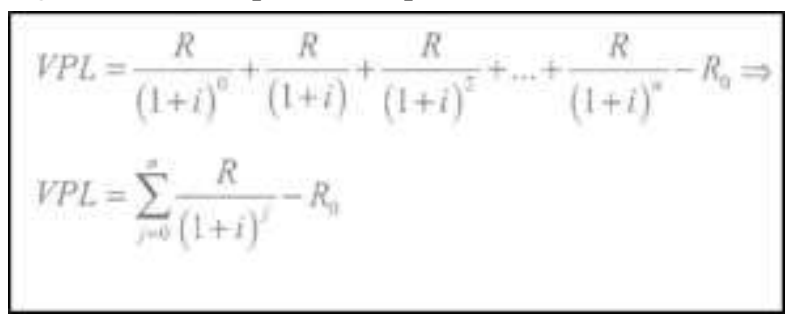

Fonte: Adaptado de Silva; Minello (2009)

\subsubsection{Taxa interna de retorno (TIR)}

De acordo com Castelo Branco (2005), a TIR é uma técnica tão ou mais sofisticada do que o VPL, que "[...] pode ser definida como a taxa de desconto que iguala os fluxos de caixa ao investimento inicial. Em outras palavras, é a taxa que produz um VPL igual a zero" (KASSAI et al, 2005, p.68).

A figura 2 expõe a fórmula da taxa interna de retorno:

Figura 2 - Taxa interna de retorno

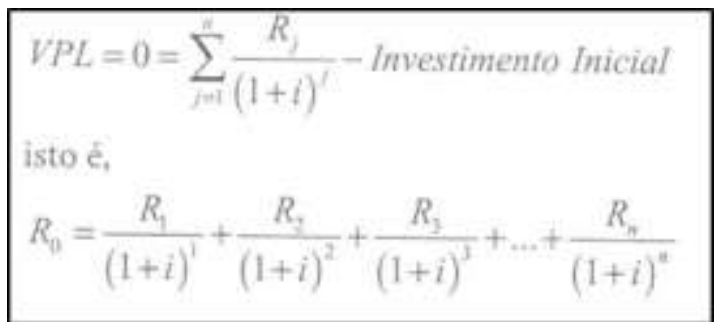

Fonte: Adaptado de Silva; Minello (2009)

\subsubsection{Payback}

“O Período de Payback (PP), também conhecido como período de recuperação, é o tempo exigido para a empresa recuperar seu investimento inicial em um projeto". (SANTOS, 2005, p. 122).

Segundo Gitman (2004), o período payback é usado para decidir entre a aceitação ou rejeição de um projeto, verificando também o período máximo aceitável de recuperação, que é determinado pela administração de cada empresa, assim como devem ser considerados os seguintes critérios:

- O projeto deve ser aceito, quando o período payback for menor que o período máximo aceitável de recuperação;

- O projeto deve ser rejeitado, quando o período payback for maior que o período máximo aceitável de recuperação.

\subsection{Análise de Econômica}

De acordo com Casarotto Filho e Kopittke (2000), na análise econômica deve-se realizar um levantamento dos custos e das receitas adicionais, que ocorrerão em virtude deste investimento.

\subsubsection{Custo do Investimento}

Para Gropelli e Nikbakht (2002, p. 123), "uma vez que os administradores saibam quanto custa a ativação de um projeto, eles podem comparar o investimento inicial com os benefícios futuros e julgar se o projeto merece ser implementado".

"Investimento é uma
utilização de recursos
(próprios ou de terceiros)
com vistas na aquisição de


um ativo, ativo este que será necessário à geração de resultados no futuro. Essa característica é que diferencia um investimento de uma despesa, uma vez que a despesa também representa uma utilização de recursos, não vinculados a um retorno futuro." (ANGELO; SILVEIRA, 2000, p.246)

\subsubsection{Custos Operacionais}

A definição dos custos operacionais é importante para que a empresa tenha noção de todos os seus gastos, desde o custo para produzir seus produtos (custos de produção) até o valor despendido na venda dos bens produzidos (despesas gerais), fornecendo subsídios para a empresa definir com mais precisão o preço de venda de seus produtos.

"Além de seu agrupamento
em Diretos e Indiretos, os
custos podem ser
classificados de outras
formas. Outra classificação
usual (e mais importante
que todas as demais) é a que
leva em consideração a
relação entre o valor total de
um custo e o volume de
atividade numa unidade de
tempo. Divide basicamente
os Custos em Fixos e
Variáveis". (MARTINS,
2010, p.49)

\subsubsection{Custos Fixos}

De acordo com Perez Jr., Oliveira e Costa (2008, p. 26), os custos fixos "são os custos que permanecem constantes dentro de determinada capacidade instalada, independem do volume de produção, ou seja, uma alteração no volume de produção para mais ou para menos não altera o valor total do custo".

\subsubsection{Custos Variáveis}

Segundo Perez Jr., Oliveira e Costa (2008), os custos variáveis estão diretamente relacionados com o volume de produção ou serviço, o que significa que se elevam, na mesma proporção com que o volume de atividades da empresa aumenta. No entanto, o valor por unidade se mantém constante, mesmo ocorrendo variações na quantidade produzida.

\subsection{Fluxo de Caixa}

Como afirma Gitman (1997), a demonstração de fluxos de caixa refere-se aos movimentos de entrada e saída de caixa durante um determinado período, que concilia os fluxos de caixa operacionais, de investimento e financiamento da empresa com as variações dos saldos de caixa e aplicações em títulos negociáveis no período considerado.

\subsection{Projeção de Receita}

A projeção de receitas de uma empresa contribui muito no processo de tomada de decisões, visto que, a mesma proporciona aos gestores um maior conhecimento da capacidade do negócio, a partir da qual a empresa poderá planejar melhor suas ações e obter um melhor desempenho.

Conforme Santos (2005, p. 47), “na prática, um dos mecanismos mais utilizados 
para a projeção das vendas baseia-se na arbitragem de uma taxa de crescimento, a partir de dados extraídos do desempenho histórico". Considerando que as expectativas refletem o desempenho passado, a projeção pode ser realizada aplicando-se uma taxa média histórica de crescimento da receita líquida de vendas.

\subsection{Previsão de Vendas}

De acordo com Martins e Laugeni (2002, p. 173), “a previsão de vendas é importante para utilizar as máquinas de maneira adequada, para realizar a reposição dos materiais no momento e na quantidade certa, e para que todas as demais atividades necessárias ao processo industrial sejam adequadamente programadas".

\subsection{Riscos e Retornos}

De acordo com Kassai et al. (2005), ao se analisar o risco envolvido em um projeto é importante não considerá-lo apenas como uma situação esperada, mas também analisá-lo sob outras duas projeções: uma mais otimista e outra mais pessimista.

"Risco é o grau de incerteza associado a um investimento. Quanto maior a volatilidade dos retornos de um investimento, maior será o seu risco. Quando dois projetos têm os mesmos retornos esperados, escolhe-se aquele de menor risco". (GROPELLI ;NIKBAKHT, 2002, p. 73)
Conforme Gitman (2004), o retorno sobre um investimento pode ser caracterizado como o ganho ou a perda total ocorrida em um determinado período. Geralmente, o retorno é medido através da soma dos proventos em dinheiro durante o período com a variação de valor, relacionando com a porcentagem do valor do investimento no início do período.

\subsection{O setor têxtil e de confecções}

Conforme dados da Associação Brasileira da Indústria Têxtil e de Confecção (ABIT), as atividades do setor têxtil e confecções já existem no país a cerca de 200 anos, e emprega atualmente cerca de 1,7 milhões de pessoas de forma direta, das quais $75 \%$ são mulheres. O Brasil é a quinta maior indústria têxtil do mundo e a quarta de confecções, porém sua participação nesse mercado é de menos de $0,4 \%$.

De acordo com Moreira (2015), a indústria têxtil obteve um resultado negativo em seu desempenho no ano de 2014, sofrendo uma queda de 5\%. O presidente da Associação Brasileira da Indústria Têxtil (ABIT), Rafael Cervone acredita que a indústria têxtil brasileira deverá passar por ajustes neste ano de 2015, e somente retomar o crescimento a partir de 2016.

\subsection{Terceirização}

De acordo com Ferreira (2013), a terceirização é uma tendência mundial e utilizada por modernas redes de produção. 
Nesta alternativa, as atividades são transferidas para empresas especializadas, que realizam o serviço utilizando-se de uma melhor tecnologia, contribuindo para o aumento de empregos e da produtividade.

Conforme Leiria (1991), a terceirização traz aspectos positivos como: diminuição do desperdício; aumento da qualidade, da produtividade, da especialização e do lucro; melhor administração do tempo da empresa, diminuição do passivo trabalhista e redução do quadro direto de empregados. Em relação, aos aspectos negativos da terceirização, pode-se enfatizar o aumento da dependência de terceiros e a má administração do processo.

\section{METODOLOGIA}

A metodologia é um conjunto de técnicas e procedimentos que tem o objetivo de viabilizar a execução da pesquisa (JUNG, 2004). Para a realização do presente estudo utilizou-se a seguinte abordagem: dedutiva, qualitativa e quantitativa. Quanto aos procedimentos caracteriza-se como descritivo (para contextualizar a empresa), comparativo (para comparar a alternativa de aquisição de uma máquina de tecelagem com a alternativa de terceirização de parte deste serviço) e estudo de caso (para obter mais conhecimento acerca da rotina da indústria de confecções, bem como as atividades relacionadas ao processo de tecelagem).

Em relação às técnicas foram utilizadas as técnicas de coleta e análise de dados. Para a coleta de dados utilizou-se: a observação (para compreender o funcionamento da indústria de confecções, em especial o processo de tecelagem), a entrevista (realizada de maneira informal, com a utilização de diálogo com o sócio gerente e funcionários da empresa) e a pesquisa documental (para realizar o levantamento de dados e informações, através de documentos, arquivos, planilhas e relatórios). Já para a análise de dados se fez uso da ferramenta Microsoft Office Excel ${ }^{\circledR}$, para realizar a tabulação dos dados coletados através das observações e entrevistas, auxiliando também na geração de gráficos e tabelas. A análise de conteúdo foi realizada a partir de dados coletados e informações obtidas na indústria de confecções, a fim de compreender a realidade da empresa.

\section{APRESENTAÇÃO E ANÁLISE DOS RESULTADOS}

\subsection{Histórico da empresa e informações adicionais}

A empresa estudada localiza-se no município de São Martinho/RS, e foi fundada em 29 de setembro de 1993. É uma Empresa de Pequeno Porte (EPP), e possui atualmente quatro sócios, sendo que cada um deles detêm $25 \%$ das quotas.

A indústria de confecções emprega seis funcionários, e produz somente peças de vestuário destinadas à estação do inverno, principalmente blusas, casacos, calças de lã e blusões masculinos. A empresa estudada é 
composta por três setores, que são: a tecelagem, a costura e por fim, a loja, onde as peças são comercializadas.

\subsection{O setor de tecelagem}

Atualmente a indústria de confecções dispõe de três máquinas de tecelagem, sendo que uma delas foi adquirida há dois anos, e produz aproximadamente 300 peças/mês, sendo estas peças mais elaboradas; outra tem dez anos de uso, e produz em média 1000 peças/mês, mas são peças menos detalhadas, também chamadas de "peças lisas".

A figura 3 refere-se à máquina de tecelagem mais nova, adquirida recentemente pela indústria de confecções. Já a figura 4 apresenta a máquina de tecelagem que possui dez anos de uso.

Figura 3 - Máquina de tecelagem recente

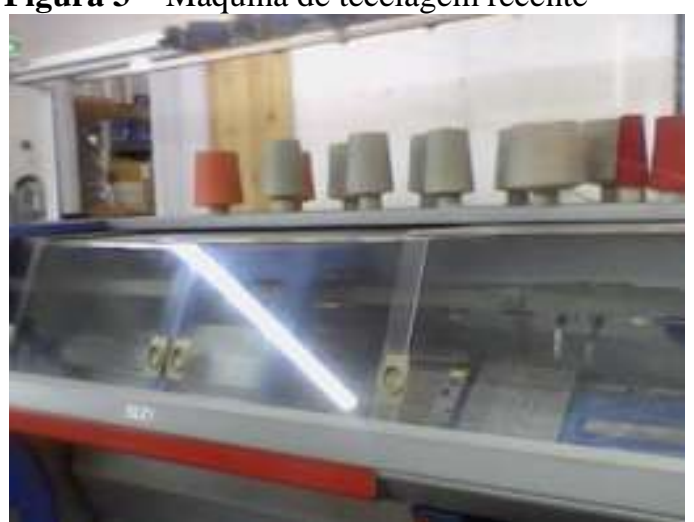

Fonte: Dados da pesquisa(2015)

Figura 4 - Máquina de tecelagem (10 anos)

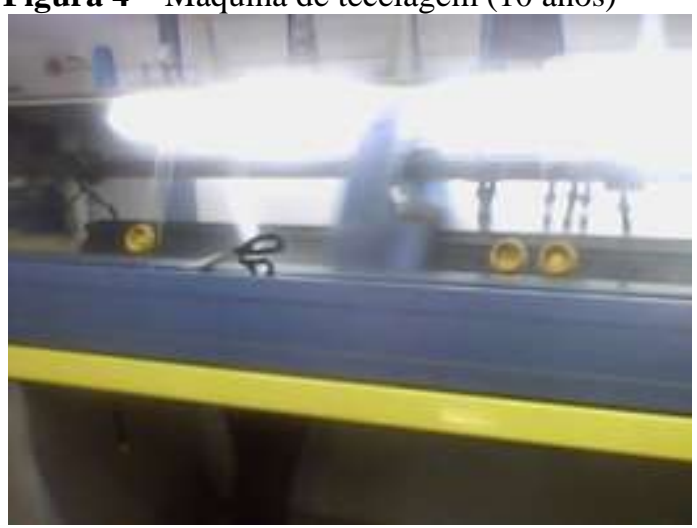

Fonte: Dados da pesquisa (2015)

A máquina de tecelagem mais antiga da indústria de confecções é apresentada na figura 5 , onde é possível verificar a inexistência de um vidro de proteção, diferente das demais máquinas de tecelagem apresentadas nas figuras anteriores. Esta máquina foi adquirida em 1993, quando a empresa iniciou suas atividades, produz cerca de 350 peças/mês, e necessita ser substituída por uma máquina mais moderna.

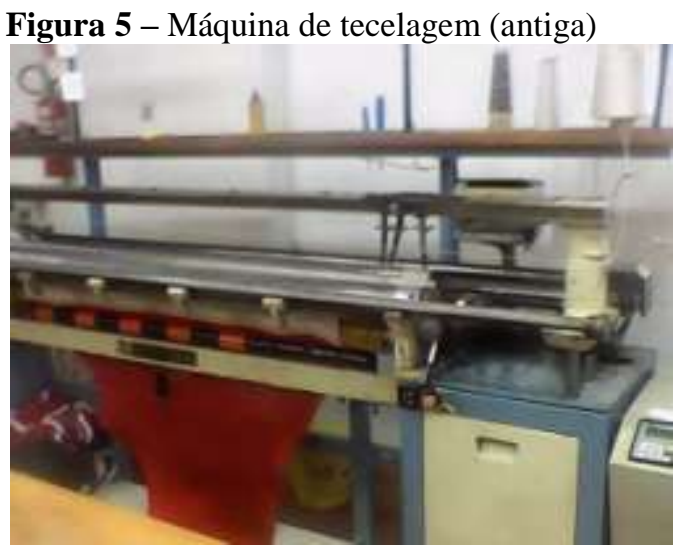

Fonte: Dados da pesquisa (2015)

No setor de tecelagem trabalham três funcionários, e cada máquina de tecelagem produz em média 2 peças/hora, mas isso depende muito do modelo confeccionado. Contudo a indústria de confecções vem estudando a possibilidade de adquirir uma máquina de tecelagem, que custa entre $R \$$ $80.000,00$ e $\mathrm{R} \$ 120.000,00$, uma vez que a empresa dispõe de espaço físico para a instalação desta máquina e um funcionário é capaz de operar três máquinas de tecelagem, ou seja, adquirindo-se uma nova máquina seria necessária apenas a contratação de uma pessoa para trabalhar no setor de costura. 


\subsection{Terceirização}

Mesmo em total funcionamento, o setor de tecelagem, não consegue atender a demanda, em alguns períodos do ano. Com o intuito de solucionar esse problema, há cerca de quatro anos a malharia optou pela terceirização, que vem sendo realizada por uma empresa de Farroupilha/RS, que trabalha com lote mínimo de cem peças por modelo, e demora entre quinze e vinte dias para realizar a entrega, dependendo da quantidade de peças solicitadas no pedido.

De acordo com o sócio gerente, o custo médio da terceirização varia entre $\mathrm{R} \$ 5,00$ e R\$ 15,00 por peça, dependendo do modelo confeccionado, sendo que geralmente são terceirizadas peças mais elaboradas/detalhadas, e neste valor não está incluso a matéria-prima, que é fornecida separadamente pela indústria de confecções.

\subsection{Histórico de produção e previsão de demanda}

De acordo com os registros existentes na indústria de confecções, foi possível analisar o histórico de produção da empresa estudada, que é demonstrado através da Tabela 1 e Figura 6.

Tabela 1 - Histórico de produção

\begin{tabular}{|c|c|}
\hline Ano & $\begin{array}{c}\text { Quantidade de peças } \\
\text { produzidas }\end{array}$ \\
\hline 2010 & 35.624 \\
\hline 2011 & 33.677 \\
\hline 2012 & 20.601 \\
\hline 2013 & 17.997 \\
\hline 2014 & 18.148 \\
\hline Projeção 2015 & 22.685 \\
\hline
\end{tabular}

Fonte: Dados da pesquisa (2015)
Figura 6 - Evolução do histórico de produção

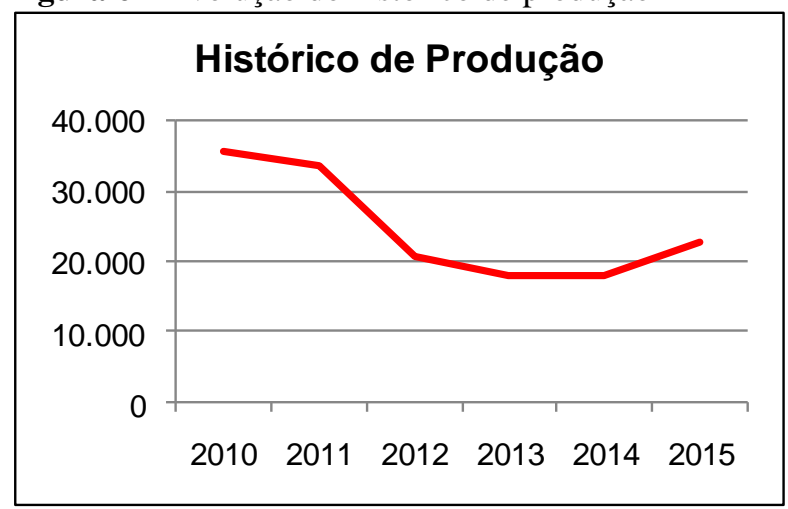

Fonte: Dados da pesquisa (2015)

Verifica-se que, a produção da indústria de confecções em anos anteriores era bem mais elevada do que atualmente, o que é explicado pelo fato da empresa estar investindo na fabricação de peças mais detalhadas, que demandam mais tempo para serem confeccionadas. Baseando-se na produção do ano de 2014, projetou-se para o ano de 2015, um aumento de $25 \%$ na produção, o que equivale a 22.685 peças a serem produzidas pela indústria de confecções.

\subsection{Vendas e projeção de receitas}

A indústria de confecções é administrada por um dos sócios, que anualmente faz uma projeção de vendas baseada nas vendas do ano anterior, e por serem produtos extremamente sazonais, também é considerada nesta projeção, a rigorosidade do inverno. Este mesmo sócio é responsável também pela compra de matériaprima e pela administração da produção.

A Tabela 2 e a Figura 7 apresentam a projeção de receitas da indústria de confecções, considerando a venda total da produção de 
cada ano. Utilizando-se desses dados, estimouse a projeção de receitas para o ano de 2015, que tem como base a produtividade da empresa estudada. Sendo assim, com a venda total da produção estimada para o ano de 2015, a receita obtida pela indústria de confecções seria de $\mathrm{R} \$ 969.065,25$.

Porém, de acordo com informações obtidas com o sócio gerente, no ano de 2014, a empresa teve um bom faturamento, mas os lojistas não realizaram boas vendas. Sendo assim, para o ano de 2015, o sócio gerente estima um faturamento de $\mathrm{R} \$ 750.000,00$, mas antecipa que esse valor será difícil de atingir, já que os lojistas ainda permanecem com estoques referentes ao ano passado.

Tabela 2 - Receitas

\begin{tabular}{|c|lc|}
\hline Ano & \multicolumn{2}{|c|}{ Projeção de receitas } \\
\hline 2010 & $\mathrm{R} \$$ & $767.139,70$ \\
\hline 2011 & $\mathrm{R} \$$ & $788.160,03$ \\
\hline 2012 & $\mathrm{R} \$$ & $544.578,40$ \\
\hline 2013 & $\mathrm{R} \$$ & $542.996,06$ \\
\hline 2014 & $\mathrm{R} \$$ & $775.252,20$ \\
\hline Projeção 2015 & $\mathrm{R} \$$ & $969.065,25$ \\
\hline
\end{tabular}

Fonte: Dados da pesquisa (2015)

Figura 7 - Evolução das receitas

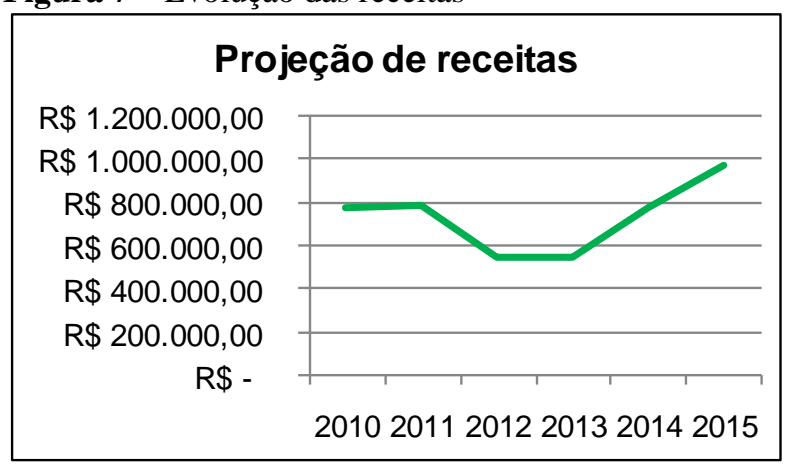

Fonte: Dados da pesquisa (2015)

\subsection{Custos fixos e variáveis}

Com relação aos custos e despesas variáveis, a indústria de confecções não possui um controle mensal destes gastos, já que se trabalha com períodos de produção. Contudo, de acordo com informações dispostas na planilha do Excel, o valor mensal correspondente aos custos fixos da empresa estudada é de R\$21.186,28. Segundo o sócio gerente, como os gastos da indústria de confecções são praticamente os mesmos, esse valor é reajustado anualmente e/ou quando há alterações significativas nos gastos.

Considerando que a indústria de confecções tem um sistema de administração baseado em períodos, pode-se dividir cada exercício em 4 trimestres:

Período de Planejamento: ocorre nos meses de setembro, outubro e novembro, quando é realizada a previsão de vendas e projeção de receitas para o ano seguinte, bem como são desenvolvidos os modelos a serem confeccionados;

Período de Produção: ocorre nos meses de dezembro, janeiro e fevereiro, quando são confeccionados os modelos de acordo com os pedidos recebidos, e também são fabricados os modelos básicos;

Período de Faturamento: nos meses de março, abril e maio acontecem as entregas dos pedidos e também o faturamento dos mesmos;

Período de Vendas Diretas: nos meses de junho, julho e agosto são realizadas as vendas diretamente ao consumidor, e a produção ocorre somente por pedidos. 
Apurou-se também que a indústria de confecções concede uma comissão de $10 \%$ sobre o faturamento para seus vendedores, e também fornece descontos que chegam a $15 \%$, para as empresas com as quais negocia suas vendas, principalmente, quando estas realizam pagamentos à vista.

\subsection{Fluxo de caixa}

De acordo com os relatórios e anotações obtidas com o sócio gerente da indústria de confecções, foi possível elaborar um fluxo de caixa para a empresa estudada, referente ao período de abril de 2014 a março de 2015. Para melhor apresentação visual, o fluxo de caixa é apresentado de forma resumida na Tabela 3:

Tabela 3 - Fluxo de caixa (resumo)

\begin{tabular}{|l|cr|}
\hline RECEBIMENTOS & R\$ & $\mathbf{6 5 0 . 0 0 0 , 0 0}$ \\
\hline Vendas à vista & $\mathrm{R} \$$ & $205.000,00$ \\
\hline Vendas à prazo & $\mathrm{R} \$$ & $445.000,00$ \\
\hline PAGAMENTOS & $\mathbf{R} \$$ & $\mathbf{5 9 0 . 0 0 7 , 5 2}$ \\
\hline Pró-labore & $\mathrm{R} \$$ & $72.000,00$ \\
\hline Fornecedor A & $\mathrm{R} \$$ & $107.000,00$ \\
\hline Fornecedor B & $\mathrm{R} \$$ & $42.995,00$ \\
\hline Fornecedor C & $\mathrm{R} \$$ & $3.277,00$ \\
\hline Telefone & $\mathrm{R} \$$ & $1.434,93$ \\
\hline Transporte & $\mathrm{R} \$$ & $5.600,00$ \\
\hline Salários & $\mathrm{R} \$$ & $108.071,40$ \\
\hline Horas extras & $\mathrm{R} \$$ & $9.700,00$ \\
\hline Comissão vendedores & $\mathrm{R} \$$ & $65.000,00$ \\
\hline Desconto em rede & $\mathrm{R} \$$ & $69.999,99$ \\
\hline Contador & $\mathrm{R} \$$ & $5.269,20$ \\
\hline Terceirização & $\mathrm{R} \$$ & $18.200,00$ \\
\hline Impostos & $\mathrm{R} \$$ & $32.500,00$ \\
\hline Impostos matéria-prima & $\mathrm{R} \$$ & $12.500,04$ \\
\hline Manutenção & $\mathrm{R} \$$ & $23.499,96$ \\
\hline Prestação do prédio & $\mathrm{R} \$$ & $12.960,00$ \\
\hline SALDO & $\mathbf{R} \$$ & $\mathbf{5 9 . 9 9 2 , 4 8}$ \\
\hline
\end{tabular}

Fonte: Dados da pesquisa (2015)

Durante o período analisado, compreendido entre abril de 2014 e março de
2015, a figura 10 mostra que a indústria de confecções obteve um faturamento de $\mathrm{R} \$$ $650.000,00$, composto pelas vendas à vista e à prazo. Com relação aos pagamentos, estes atingiram o valor de $\mathrm{R} \$ 590.007,52$, os quais subtraídos dos recebimentos obtidos neste período resultam em um saldo positivo de $\mathrm{R} \$$ 59.992,48. Destaca-se também o valor de R\$ 18.200,00, correspondente ao serviço de terceirização de peças durante o período considerado, sendo esta uma alternativa adotada pela indústria de confecções, em alguns meses do ano, em razão da alta demanda pelos produtos.

\subsection{Investimento}

Para a aquisição da máquina de tecelagem, a indústria de confecções necessita de um investimento estimado em R\$ 120.000,00. Esse valor poderia ser obtido junto ao Banco Nacional do Desenvolvimento (BNDES), uma vez que a empresa estudada já realiza negócios através do cartão desta instituição financeira, e por intermédio deste seria possível financiar esse empréstimo em até quarenta e oito meses, a uma baixa taxa de juros.

Partindo-se do pressuposto de que a indústria de confecções opte por adquirir a máquina de tecelagem, e realize o empréstimo no valor de $\mathrm{R} \$ 120.000,00$ através do cartão BNDES, considera-se que este empréstimo seja liquidado em doze meses, e que a taxa anual aplicada seja de $11,04 \%$. 
A Tabela 4 demonstra o investimento, sob essas condições, onde é possível verificar que o empréstimo realizado pela indústria de confecções teria parcelas mensais fixas de $\mathrm{R} \$$ $10.578,80$, valor sobre o qual incidiria a taxa mensal de $0,92 \%$, resultando em um valor total de $\mathrm{R} \$ 128.016,17$ a ser pago pela empresa, em razão do investimento na aquisição da máquina de tecelagem.

Tabela 4 - Investimento

\begin{tabular}{|c|rc|rr|}
\hline Parcela & \multicolumn{2}{|c|}{ Valor } & \multicolumn{2}{|c|}{ Total } \\
\hline 1 & $\mathrm{R} \$ 10.578,80$ & $\mathrm{R} \$$ & $10.578,80$ \\
\hline 2 & $\mathrm{R} \$ 10.578,80$ & $\mathrm{R} \$$ & $21.254,92$ \\
\hline 3 & $\mathrm{R} \$ 10.578,80$ & $\mathrm{R} \$$ & $31.931,05$ \\
\hline 4 & $\mathrm{R} \$ 10.578,80$ & $\mathrm{R} \$$ & $42.607,17$ \\
\hline 5 & $\mathrm{R} \$ 10.578,80$ & $\mathrm{R} \$$ & $53.283,30$ \\
\hline 6 & $\mathrm{R} \$ 10.578,80$ & $\mathrm{R} \$$ & $63.959,42$ \\
\hline 7 & $\mathrm{R} \$ 10.578,80$ & $\mathrm{R} \$$ & $74.635,55$ \\
\hline 8 & $\mathrm{R} \$ 10.578,80$ & $\mathrm{R} \$$ & $85.311,67$ \\
\hline 9 & $\mathrm{R} \$ 10.578,80$ & $\mathrm{R} \$$ & $95.987,80$ \\
\hline 10 & $\mathrm{R} \$ 10.578,80$ & $\mathrm{R} \$$ & $106.663,92$ \\
\hline 11 & $\mathrm{R} \$ 10.578,80$ & $\mathrm{R} \$$ & $117.340,05$ \\
\hline 12 & $\mathrm{R} \$ 10.578,80$ & $\mathrm{R} \$$ & $128.016,17$ \\
\hline
\end{tabular}

Fonte: Dados da pesquisa (2015)

\subsection{Cenários}

Na elaboração destes cenários, que são representados por "ótimo", "bom" e "razoável”, parte-se do pressuposto de que a empresa estudada, adquirindo a máquina de tecelagem, contratasse apenas uma costureira (que trabalharia os doze meses do ano), considerando-se ainda, para fins desta análise, o último valor gasto no ano com a terceirização (que ocorre durante seis meses do ano).

A Tabela 5 apresenta a Projeção de Cenários, onde se verifica que, contratando uma costureira para trabalhar doze meses, a indústria de confecções gastaria $\mathrm{R}$ \$ 975,64 a mais por ano, em relação à terceirização. No entanto, com a aquisição da máquina de tecelagem e mais mão de obra, a empresa poderia aumentar sua produção em até $30 \%$, o equivalente a R\$225.000,00 por ano, como demonstra o cenário "ótimo". Além disso, nota-se também que a indústria de confecções obteria um ganho de aproximadamente $\mathrm{R} \$$ $5.460,00$, se a empresa terceirizada trabalhar com uma margem de lucro de cerca de $30 \%$.

Tabela 5 - Projeção de cenários

\begin{tabular}{|l|c|c|c|}
\hline \multicolumn{1}{|c|}{ Descrição } & Ótimo & Bom & Razoável \\
\cline { 2 - 4 } & $18.200,00$ & $18.200,00$ & $18.200,00$ \\
\hline $\begin{array}{l}\text { Terceirização } \\
(\mathrm{R} \$)\end{array}$ & $19.175,64$ & $19.175,64$ & $19.175,64$ \\
\hline Costureira (R\$) & $30 \%$ & $30 \%$ & $30 \%$ \\
\hline $\begin{array}{l}\text { Diferença mão } \\
\text { de obra (R\$) }\end{array}$ & $-975,64$ & $-975,64$ & $-975,64$ \\
\hline $\begin{array}{l}\text { Margem de lucro } \\
\text { terceirizada }\end{array}$ & $5.460,00$ & $5.460,00$ & $5.460,00$ \\
\hline $\begin{array}{l}\text { Lucro } \\
\text { terceirizada (R\$) }\end{array}$ & $30 \%$ & $20 \%$ & $10 \%$ \\
\hline $\begin{array}{l}\text { Projeção vendas } \\
\text { produção 2015 }\end{array}$ & $750.000,00$ & $750.000,00$ & $750.000,00$ \\
\hline $\begin{array}{l}\text { \% aumento } \\
\text { produtividade }\end{array}$ & $225.000,00$ & $150.000,00$ & $\mathbf{7 5 . 0 0 0 , 0 0}$ \\
\hline $\begin{array}{l}\text { Aumento } \\
\text { produtividade } \\
\text { (R\$) }\end{array}$ & $\mathbf{2 2 9 . 4 8 4 , 3 6}$ & $\mathbf{1 5 4 . 4 8 4 , 3 6}$ & $\mathbf{7 9 . 4 8 4 , 3 6}$ \\
\hline $\begin{array}{l}\text { Ganhos totais } \\
\text { (R\$) }\end{array}$ &
\end{tabular}

Fonte: Dados da pesquisa (2015)

No cenário "bom", considera-se que a indústria de confecções, optando pelo investimento, poderia aumentar sua produtividade em 20\%, o que geraria à empresa ganhos totais acima de $R \$$ 150.000,00. Por fim, no cenário "razoável" verifica-se que um aumento de apenas $10 \%$ na produção da indústria de confecções, resultará em um incremento de cerca de $\mathrm{R} \$ 75.000,00$ em sua receita, ao término do exercício.

Analisando os três cenários apresentados é possível perceber que todos eles 
remetem à positividade do investimento na aquisição da máquina de tecelagem, considerando um aumento na produção.

\subsection{Demonstração do resultado do exercício (DRE) projetada}

A Demonstração do Resultado do Exercício (DRE) projetada para os três cenários, baseia-se em um aumento nas receitas de $30 \%, 20 \%$ e $10 \%$, respectivamente, em relação ao faturamento estimado para a indústria de confecções, nas condições atuais, sendo projetada para os próximos 5 (cinco) anos, a partir do cenário atual da empresa, onde se considera para o primeiro ano, um faturamento de $\mathrm{R} \$ 750.000,00$ (estimado pelo sócio gerente).

A Tabela 6 apresenta a DRE Projetada para a indústria de confecções, que foi desenvolvida a partir dos dados extraídos do fluxo de caixa elaborado para a empresa estudada. No cenário atual, devido ao aumento estimado para o faturamento da empresa, projetou-se um acréscimo de $15 \%$ no custo das mercadorias vendidas, no pró-labore e também nos gastos com a terceirização, uma vez que, havendo um maior faturamento há também a necessidade de aumentar a produção, elevando os custos com matéria-prima e mão de obra.

Nos três cenários projetados para a indústria de confecções, considera-se a hipótese de aquisição de uma máquina de tecelagem pela empresa, na qual se elimina os gastos com a terceirização, mas ocasiona um aumento de $\mathrm{R} \$ 19.175,64$ no valor gasto com os salários, que se refere ao custo com a contratação de uma costureira.

Tabela 6 - DRE projetada

\begin{tabular}{|l|c|c|c|c|}
\hline \multirow{2}{*}{ Descrição } & \multicolumn{4}{|c|}{ Cenários projetados (R\$) } \\
\cline { 2 - 5 } & Atual & Ótimo & Bom & Razoável \\
\hline Receita bruta & 750.000 & 975.000 & 900.000 & 825.000 \\
\hline Receita líquida & 667.500 & 867.750 & 801.000 & 734.250 \\
\hline Lucro bruto & 491.237 & 638.608 & 589.485 & 540.361 \\
\hline $\begin{array}{l}\text { Despesas } \\
\text { trabalhistas }\end{array}$ & 218.237 & 302.884 & 281.060 & 259.236 \\
\hline $\begin{array}{l}\text { Despesas } \\
\text { administrativas }\end{array}$ & 131.045 & 143.150 & 132.138 & 121.127 \\
\hline $\begin{array}{l}\text { Despesas } \\
\text { financeiras }\end{array}$ & 27.335 & 159.664 & 158.226 & 156.789 \\
\hline $\begin{array}{l}\text { Resultado } \\
\text { líquido }\end{array}$ & 114.620 & 32.911 & 18.060 & 3.209 \\
\hline $\begin{array}{l}\text { Lucro líquido } \\
\text { do exercício }\end{array}$ & $\mathbf{1 1 4 . 6 2 0}$ & $\mathbf{3 2 . 9 1 1}$ & $\mathbf{1 8 . 0 6 0}$ & $\mathbf{3 . 2 0 9}$ \\
\hline \multicolumn{1}{|c|}{$2^{\circ}$ Ano } & 121.497 & 34.886 & 19.144 & 3.402 \\
\hline $3^{\circ}$ Ano & 128.787 & 36.979 & 20.292 & 3.606 \\
\hline $4^{\circ}$ Ano & 136.514 & 39.198 & 21.510 & 3.822 \\
\hline $5^{\circ}$ Ano & 144.705 & 41.549 & 22.800 & 4.051 \\
\hline
\end{tabular}

Fonte: Dados da pesquisa (2015)

A Tabela 6 mostra ainda uma significativa redução no lucro líquido da empresa, nos três cenários projetados ("ótimo", "bom" e "razoável"), ocasionado pelo desconto do empréstimo de $\mathrm{R} \$ 128.016,17$, realizado pela indústria de confecções em razão do investimento. Para todos os cenários projetados, inclusive o que mantém as condições atuais da empresa, estimou-se um aumento anual de $6 \%$ no lucro líquido da indústria de confecções.

\subsection{Valor presente líquido (VPL) e taxa interna de retorno (TIR)}

A partir da DRE Projetada calculou-se o VPL e a TIR, para cada um dos cenários 
projetados, denominados como "ótimo", "bom" e "razoável". Para o desenvolvimento desses cálculos utilizou-se a diferença (ganhos) entre o lucro líquido estimado para os cenários projetados (com a aquisição da máquina de tecelagem) em relação ao lucro líquido projetado para o cenário atual, sendo que o valor do investimento referente à aquisição da máquina de tecelagem, presente na DRE Projetada, foi descontado do lucro líquido estimado para cada um dos cenários analisados, considerando ainda um acréscimo anual de $6 \%$ em relação ao primeiro ano.

A Tabela 7 apresenta o cálculo do VPL e da TIR para os três cenários projetados, onde se pode visualizar que, tanto o cálculo do VPL quanto da TIR resulta em valores positivos para o cenário "ótimo" e "bom", indicando a viabilidade do investimento, uma vez que, convertendo-se os valores futuramente investidos na aquisição da máquina de tecelagem, tem-se um Valor Presente Líquido de $\mathrm{R} \$$ 62.411,40 para o cenário “ótimo” e R \$

\subsection{0,33 para o cenário "bom”.}

Tabela 7 - Cálculo do VPL e da TIR para os cenários projetados

\begin{tabular}{|c|c|c|c|c|}
\hline \multirow{2}{*}{\multicolumn{2}{|c|}{$\begin{array}{l}\text { Projeção de } \\
\text { receitas }\end{array}$}} & \multicolumn{3}{|c|}{ Cenários projetados (R\$) } \\
\hline & & Ótimo & Bom & Razoável \\
\hline \multicolumn{2}{|c|}{ Investimento } & $-128.016,17$ & $-128.016,17$ & $-128.016,17$ \\
\hline \multirow{5}{*}{ 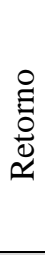 } & $1^{\circ}$ Ano & $46.307,34$ & $31.456,34$ & $16.605,35$ \\
\hline & $2^{\circ}$ Ano & $49.085,78$ & $33.343,72$ & $17.601,67$ \\
\hline & $3^{\circ}$ Ano & $52.030,92$ & $35.344,35$ & $18.657,77$ \\
\hline & $4^{\circ}$ Ano & $55.152,78$ & $37.465,01$ & $19.777,24$ \\
\hline & $5^{\circ}$ Ano & $58.461,94$ & $39.712,91$ & $20.963,87$ \\
\hline \multicolumn{2}{|r|}{ VPL } & $62.411,40$ & $1.340,33$ & $-59.730,73$ \\
\hline \multicolumn{2}{|r|}{ TIR } & $28,19 \%$ & $11,44 \%$ & $-9,28 \%$ \\
\hline
\end{tabular}

Fonte: Dados da pesquisa (2015)
Além disso, para ambos os cenários, a TIR encontrada é superior à taxa de $11,04 \%$ do Banco BNDES, que representa a Taxa Mínima de Atratividade do investimento, o que significa que a indústria de confecções obteria maior lucratividade adquirindo a máquina de tecelagem, do que aplicando o dinheiro na instituição financeira.

A Tabela 7 indica que no cenário "razoável", a aquisição da máquina de tecelagem não é favorável para a indústria de confecções, pois o cálculo do VPL e da TIR apresenta resultados negativos, ou seja, haveria um prejuízo de $\mathrm{R} \$$ 59.730,73, se a empresa realizasse o investimento sob essas condições.

Com base no cálculo do VPL e da TIR, verifica-se que o investimento na aquisição da máquina de tecelagem só é viável para a indústria de confecções, se a mesma aumentar seu faturamento em pelo menos $20 \%$, caso contrário, manter a alternativa de terceirização torna-se mais lucrativo para a empresa.

\subsection{Payback simples descontado}

Complementando a análise de indicadores, para cada um dos três cenários projetados para a indústria de confecções, calculou-se o payback simples e o payback descontado, utilizando-se dos valores referentes ao lucro líquido obtido com o investimento nos próximos cinco anos, para as três situações expostas. 
A Tabela 8 apresenta o cálculo do payback simples para o cenário “ótimo”, no qual o retorno do investimento é inferior a três anos, o que indica um bom investimento. Além disso, ao final dos cincos anos, a empresa terá faturado $\mathrm{R} \$ 261.038,76$, o que equivale a um retorno de $204 \%$, sobre o valor investido inicialmente.

Tabela 8-Payback simples para o cenário "ótimo"

\begin{tabular}{|c|c|c|c|c|}
\hline \multicolumn{5}{|c|}{ Cenário "ótimo" } \\
\hline Ano & Investimento & $\begin{array}{c}\text { Fluxo de } \\
\text { caixa simples }\end{array}$ & Ano & $\begin{array}{l}\text { Total } \\
\text { ano }\end{array}$ \\
\hline 0 & -128.016 & & & \\
\hline 1 & & 46.307 & $36 \%$ & $36 \%$ \\
\hline 2 & & 49.086 & $38 \%$ & $75 \%$ \\
\hline 3 & & 52.031 & $41 \%$ & $115 \%$ \\
\hline 4 & & 55.153 & $43 \%$ & $158 \%$ \\
\hline 5 & & 58.462 & $46 \%$ & $204 \%$ \\
\hline \multicolumn{2}{|c|}{ Total recuperado } & 261.039 & & \\
\hline \multicolumn{2}{|c|}{$\begin{array}{l}\text { Período de } \\
\text { recuperação }\end{array}$} & $\begin{array}{c}\text { Valor já } \\
\text { recuperado }\end{array}$ & $\begin{array}{c}\text { A } \\
\text { recuperar }\end{array}$ & \\
\hline Anos & 2 & 95.393 & 32.623 & \\
\hline Meses & 7,5 & & & \\
\hline Dias & 15,7 & & & \\
\hline $\begin{array}{c}\text { Payback } \\
\text { simples }\end{array}$ & 2 anos & 7 meses & 16 dias & \\
\hline
\end{tabular}

Fonte: Dados da pesquisa (2015)

Nota-se na Tabela 9, no cálculo do payback descontado para o cenário "ótimo", que o valor das receitas projetadas para os próximos cinco anos são descapitalizados, utilizando-se a taxa de $11,04 \%$ do Banco BNDES, informando os valores no tempo presente, tornando o resultado obtido com o cálculo do payback, mais próximo da realidade.

Tabela 9 - Payback descontado para o cenário "ótimo"

\begin{tabular}{|c|c|c|c|c|}
\hline \multicolumn{5}{|c|}{ Cenário "ótimo" } \\
\hline Ano & Investimento & $\begin{array}{c}\text { Fluxo de } \\
\text { caixa simples }\end{array}$ & Ano & $\begin{array}{c}\text { Total } \\
\text { ano }\end{array}$ \\
\hline 0 & -128.016 & & & \\
\hline 1 & & 41.703 & $33 \%$ & $33 \%$ \\
\hline 2 & & 39.810 & $31 \%$ & $64 \%$ \\
\hline 3 & & 38.003 & $30 \%$ & $93 \%$ \\
\hline 4 & & 36.278 & $28 \%$ & $122 \%$ \\
\hline 5 & & 34.631 & $27 \%$ & $149 \%$ \\
\hline
\end{tabular}

\begin{tabular}{|l|c|c|c|}
\multicolumn{2}{|c|}{ Total recuperado } & $\mathbf{1 9 0 . 4 2 7}$ & \\
\hline $\begin{array}{c}\text { Período de } \\
\text { recuperação }\end{array}$ & $\begin{array}{c}\text { Valor já } \\
\text { recuperado }\end{array}$ & $\begin{array}{c}\text { A } \\
\text { recuperar }\end{array}$ \\
\hline Anos & 3 & 119.517 & 8.499 \\
\hline Meses & 2,8 & & \\
\hline Dias & 24,3 & & \\
\hline $\begin{array}{l}\text { Payback } \\
\text { simples }\end{array}$ & $\mathbf{3}$ anos & $\mathbf{2}$ meses & $\mathbf{2 4}$ dias \\
\hline
\end{tabular}

Fonte: Dados da pesquisa (2015)

Conforme mostra a Tabela 9, realizando o investimento, depois de transcorrido os cinco anos analisados, a indústria de confecções terá atingido um faturamento de $\mathrm{R} \$ 190.427,57$, o que representa um retorno de $149 \%$ sobre o capital investido, indicando que a aquisição da máquina de tecelagem é um investimento lucrativo.

Em relação ao cenário "bom", a Tabela 10 e Tabela 11, apresentam o payback simples e o payback descontado respectivamente:

Tabela 10 - Payback simples para o cenário "bom"

\begin{tabular}{|c|c|c|c|c|}
\hline \multicolumn{5}{|c|}{ Cenário "bom" } \\
\hline Ano & Investimento & $\begin{array}{c}\text { Fluxo de } \\
\text { caixa simples }\end{array}$ & Ano & $\begin{array}{c}\text { Total } \\
\text { ano }\end{array}$ \\
\hline 0 & -128.016 & & & \\
\hline 1 & & 31.456 & $25 \%$ & $25 \%$ \\
\hline 2 & & 33.343 & $26 \%$ & $51 \%$ \\
\hline 3 & & 35.344 & $28 \%$ & $78 \%$ \\
\hline 4 & & 37.465 & $29 \%$ & $107 \%$ \\
\hline 5 & & 39.712 & $31 \%$ & $139 \%$ \\
\hline \multicolumn{2}{|c|}{ Total recuperado } & $\mathbf{1 7 7 . 3 2 2}$ & & \\
\hline \multicolumn{2}{|c|}{$\begin{array}{l}\text { Período de } \\
\text { recuperação }\end{array}$} & $\begin{array}{c}\text { Valor já } \\
\text { recuperado }\end{array}$ & $\begin{array}{c}\text { A } \\
\text { recuperar }\end{array}$ & \\
\hline Anos & 3 & 100.144 & 27.871 & \\
\hline Meses & 8,9 & & & \\
\hline Dias & 27,8 & & & \\
\hline $\begin{array}{c}\text { Payback } \\
\text { simples }\end{array}$ & 3 anos & 8 meses & 28 dias & \\
\hline
\end{tabular}

Através da Tabela 10, verifica-se que o investimento na aquisição de uma máquina de tecelagem é viável para a empresa estudada, uma vez que, o mesmo será recuperado em menos de quatro anos, e somando-se as receitas 
projetadas para os cinco anos, tem-se um valor recuperado superior ao valor investido.

Na Tabela 11, constata-se que o valor investido na aquisição da máquina de tecelagem é recuperado pela indústria de confecções em quatro anos, onze meses e nove dias. Sendo assim, verifica-se que nas condições projetadas para esse cenário, o investimento analisado ainda é favorável para a indústria de confecções, embora a Tabela 11 demonstre que a empresa obterá, ao final do período considerado, um lucro de apenas $1 \%$ em relação ao capital investido.

Tabela 11 - Payback descontado para o cenário "bom"

\begin{tabular}{|c|c|c|c|c|}
\hline \multicolumn{5}{|c|}{ Cenário "bom" } \\
\hline Ano & Investimento & $\begin{array}{c}\text { Fluxo de } \\
\text { caixa simples }\end{array}$ & Ano & $\begin{array}{c}\text { Total } \\
\text { ano }\end{array}$ \\
\hline 0 & -128.016 & & & \\
\hline 1 & & 28.328 & $22 \%$ & $22 \%$ \\
\hline 2 & & 27.043 & $21 \%$ & $43 \%$ \\
\hline 3 & & 25.815 & $20 \%$ & $63 \%$ \\
\hline 4 & & 24.643 & $19 \%$ & $83 \%$ \\
\hline 5 & & 23.525 & $18 \%$ & $101 \%$ \\
\hline \multicolumn{2}{|c|}{ Total recuperado } & 129.356 & & \\
\hline \multicolumn{2}{|c|}{$\begin{array}{c}\text { Período de } \\
\text { recuperação }\end{array}$} & $\begin{array}{c}\text { Valor já } \\
\text { recuperado }\end{array}$ & $\begin{array}{c}\text { A } \\
\text { recuperar }\end{array}$ & \\
\hline Anos & 4 & 105.831 & 22.184 & \\
\hline Meses & 11,3 & & & \\
\hline Dias & 9,5 & & & \\
\hline $\begin{array}{l}\text { Payback } \\
\text { simples }\end{array}$ & 4 anos & 11 meses & 9 dias & \\
\hline
\end{tabular}

Fonte: Dados da pesquisa (2015)

Visualiza-se na Tabela 12, que a indústria de confecções optando por realizar o investimento, sob essas condições, não obterá o retorno do capital investido no período considerado, uma vez que, no quinto ano a empresa ainda necessitará de $\mathrm{R} \$ 34.410,26$ para atingir o valor investido inicialmente na aquisição da máquina de tecelagem, tendo recuperado apenas $73 \%$ do investimento.
Tabela 12 - Payback simples para o cenário "razoável"

\begin{tabular}{|c|c|c|c|c|}
\hline \multicolumn{5}{|c|}{ Cenário "razoável" } \\
\hline Ano & Investimento & $\begin{array}{c}\text { Fluxo de } \\
\text { caixa simples }\end{array}$ & Ano & $\begin{array}{c}\text { Total } \\
\text { ano }\end{array}$ \\
\hline 0 & -128.016 & & & \\
\hline 1 & & 16.605 & $13 \%$ & $13 \%$ \\
\hline 2 & & 17.601 & $14 \%$ & $27 \%$ \\
\hline 3 & & 18.657 & $15 \%$ & $41 \%$ \\
\hline 4 & & 19.777 & $15 \%$ & $57 \%$ \\
\hline 5 & & 20.963 & $16 \%$ & $73 \%$ \\
\hline \multicolumn{2}{|c|}{ Total recuperado } & 93.605 & & \\
\hline \multicolumn{2}{|c|}{$\begin{array}{l}\text { Período de } \\
\text { recuperação }\end{array}$} & $\begin{array}{c}\text { Valor já } \\
\text { recuperado }\end{array}$ & $\begin{array}{c}\text { A } \\
\text { recuperar }\end{array}$ & \\
\hline Anos & 5 & 93.605 & 34.410 & \\
\hline $\begin{array}{c}\text { Payback } \\
\text { simples }\end{array}$ & \multicolumn{3}{|c|}{ Em 5 anos se mostra inviável } & \\
\hline
\end{tabular}

Fonte: Dados da pesquisa (2015)

Conforme mostra a Tabela 13, o cálculo do payback descontado, indica que no cenário "razoável", o investimento na aquisição da máquina de tecelagem, em cinco anos se mostra inviável para a empresa.

Tabela 13 - Payback descontado para o cenário "razoável"

\begin{tabular}{|c|c|c|c|c|}
\hline \multicolumn{5}{|c|}{ Cenário "razoável" } \\
\hline Ano & Investimento & $\begin{array}{c}\text { Fluxo de } \\
\text { caixa simples }\end{array}$ & Ano & $\begin{array}{c}\text { Total } \\
\text { ano }\end{array}$ \\
\hline 0 & -128.016 & & & \\
\hline 1 & & 14.954 & $12 \%$ & $12 \%$ \\
\hline 2 & & 14.275 & $11 \%$ & $23 \%$ \\
\hline 3 & & 13.627 & $11 \%$ & $33 \%$ \\
\hline 4 & & 13.009 & $10 \%$ & $44 \%$ \\
\hline 5 & & 12.418 & $10 \%$ & $53 \%$ \\
\hline \multicolumn{2}{|c|}{ Total recuperado } & 68.285 & & \\
\hline \multicolumn{2}{|c|}{$\begin{array}{l}\text { Período de } \\
\text { recuperação }\end{array}$} & $\begin{array}{c}\text { Valor já } \\
\text { recuperado }\end{array}$ & $\begin{array}{c}\text { A } \\
\text { recuperar }\end{array}$ & \\
\hline Anos & 5 & 68.285 & 59.730 & \\
\hline $\begin{array}{c}\text { Payback } \\
\text { simples }\end{array}$ & \multicolumn{3}{|c|}{ Em 5 anos se mostra inviável } & \\
\hline
\end{tabular}

Fonte: Dados da pesquisa (2015)

Por fim, analisando o payback simples e descontado para os três cenários projetados, verifica-se que somente no cenário "ótimo" e "bom", o investimento na aquisição da máquina de tecelagem é viável para a empresa estudada, confirmando os resultados já obtidos com o cálculo do VPL e da TIR. 


\subsection{Alternativa mais vantajosa para a empresa}

De acordo com o estudo, pode-se considerar que a terceirização é a alternativa mais indicada para a empresa estudada, se a mesma mantiver a produção atual. Porém ao aumentar a produção, e elevar o faturamento, em pelo menos $20 \%$, a aquisição da máquina de tecelagem passaria a ser uma alternativa viável e a mais vantajosa para a empresa estudada.

\section{CONCLUSÃO}

O presente trabalho teve como objetivo geral, analisar a viabilidade econômica e financeira da aquisição de uma máquina de tecelagem comparando com a alternativa de terceirização de parte deste serviço, em uma indústria de confecções, localizada na região Noroeste do estado do Rio Grande do Sul, cujo problema de pesquisa visava identificar qual destas alternativas é mais vantajosa para a indústria de confecções.

O estudo atingiu todos os objetivos propostos, e apontou que nas condições atuais da empresa, a alternativa de terceirização apresenta-se mais vantajosa do que a aquisição de uma máquina de tecelagem. Todavia, considerando-se um percentual de aumento na produtividade da indústria de confecções, que seja igual ou superior a $20 \%$, a alternativa de aquisição de uma máquina de tecelagem torna- se viável e também mais vantajosa do que a terceirização.

Embora a alternativa de terceirização seja a mais indicada para a empresa nas condições atuais, deve-se considerar que esta estratégia também traz riscos à empresa. Deste modo, considerando que ambas as alternativas têm suas vantagens e desvantagens, cabe aos sócios da indústria de confecções analisar a possibilidade de aumentar a produção, para posteriormente decidir entre essas alternativas. Sugere-se que, em outra oportunidade sejam realizados novos estudos na indústria de confecções, como os relacionados à análise de mercado.

\section{REFERÊNCIAS BIBLIOGRÁFICAS}

\begin{abstract}
ABIT. Associação Brasileira da Indústria Têxtil e de Confecção. 2013. Indústria Têxtil e de Confecção Brasileira. [Adobe Acrobat]. Acessado em 17/06/2015. Disponível em <http://www.abit.org.br/conteudo/links/publica coes/cartilha_rtcc.pdf.
\end{abstract}

. 2014. Agenda de Prioridades Têxtil

de Confecção 2015 a 2018. [Adobe Acrobat]. Acessado em 16/09/2014. Disponível em $<$ http://www.abit.org.br/conteudo/links/publica coes/agenda_site.pdf $>$.

ANGELO, Claudio Felisoni de; SILVEIRA, José Augusto Giesbrecht da. (Coord.). 2000. Finanças no Varejo: gestão operacional: exercícios práticos com respostas/PROVAR. 2. ed. São Paulo: Atlas. ISBN 85-224-2506-X.

\section{CARTÃO BNDES. 2015. Cartão do Banco} Nacional do Desenvolvimento. [online]. Acessado em 01/04/2015. Disponível em <https://www.cartaobndes.gov.br/cartaobndes/ $>$. 
CASAROTTO FILHO, Nelson; KOPITTKE, Bruno Hartmut. 2000. Análise de investimentos: matemática financeira, engenharia econômica, tomada de decisão, estratégia empresarial. 9. ed. São Paulo: Atlas. ISBN 85-224-2572-8.

CASTELO BRANCO, Anísio Costa. 2005. Matemática financeira aplicada: método algébrico, HP - 12C, Microsoft Excel. 2. ed. rev. São Paulo: Pioneira Thomson Learning. ISBN 85-221-0503-0.

E \& R (Emprego e Renda). 2013. Confecção de roupas: mercado em expansão. [online]. Acessado em 03/09/2014. Disponível em <empregoerenda.com.br/ideias-denegocios/materias/1263-confeccao-de-roupasmercado-em-expansao>.

FERREIRA, Paulo Afonso. 2013. A importância da terceirização. [online]. Acessado em 07/03/2015. Disponível em <http://www.portaldaindustria.com.br/cni/ iniciativas/programas/terceirizacao/artigos/201 3/07/1,19115/a-importancia-da-terceirizacaopaulo-afonso-ferreira.html>.

GITMAN, Lawrence Jeffrey. 1997. Princípios de Administração Financeira. 7. ed. São Paulo: Harbra. ISBN 85-294-0060-7.

\section{Princípios de Administração}

Financeira. Tradução técnica Antonio Zoratto Sanvicente. 10. ed. São Paulo: Addison Wesley. ISBN 85-88639-12-2.

HOJI, Masakazu. Administração Financeira. 2 ed. São Paulo: Atlas, 2003

GROPELLI, A. A; NIKBAKHT, Ehsan. 2002. Administração Financeira. Trad. Célio Knipel Moreira. - 2. ed. São Paulo: Saraiva. ISBN 85-02-03902-4.

JUNG, Carlos Fernando. Metodologia para pesquisa e desenvolvimento - aplicada a novas tecnologias, produtos e processos. Rio de Janeiro: Axcel books do Brasil Editora Ltda, 2004.
KASSAI, Jose Roberto; CASANOVA, Silvia Pereira de Castro; SANTOS, Ariovaldo dos; NETO, Alexandre Assaf. 2005. Retorno de Investimento: abordagem matemática e contábil do lucro empresarial. 3. ed. São Paulo: Atlas. ISBN 85-224-4141-3.

LEIRIA, Jerônimo Souto. 1991.

Terceirização: uma alternativa de flexibilidade empresarial. Porto Alegre: Ed. Ortiz. ISBN 8585279-24-9.

LOVATO, Adalberto. 2013. Metodologia da Pesquisa. Três de Maio: SETREM. ISBN 97885-99020-05-0.

MARTINS, Eliseu. 2010. Contabilidade de Custos. 10. ed. São Paulo: Atlas. ISBN 97885-224-5940-7.

MARTINS, Petrônio Garcia; LAUGENI, Fernando Piero. 2002. Administração da Produção. São Paulo: Saraiva. ISBN 85-0202502-3.

PEREZ JR., José Hernandez; OLIVEIRA, Luís Martins de; COSTA, Rogério Guedes. 2008. Gestão estratégica de custos. 5. ed. 2. reimpr. São Paulo: Atlas. ISBN 978-85-224-4417-5.

SANTOS, José Odálio dos. 2005. Avaliação de empresas: cálculo e interpretação do valor das empresas: um guia prático. São Paulo: Saraiva. ISBN 85-02-05117-2.

SILVA, Marcelo Rodrigues da; MINELLO, Roberto Domingues. 2009. Matemática financeira e comercial. Rio de Janeiro: Ed. Ferreira. ISBN 978-85-7842-079-6. 